\title{
New Concepts in Diagnostics for Invasive Mycoses: Non-Culture-Based Methodologies
}

\author{
Thomas F. Patterson * and J. Peter Donnelly \\ Division of Infectious Diseases, San Antonio Center for Medical Mycology, The University of Texas Health \\ Science Center at San Antonio and the South Texas Veterans Health Care System, \\ 7703 Floyd Curl Drive-MSC 7881, San Antonio, TX 78229-3900, USA; p.donnelly@usa.net \\ * Correspondence: patterson@uthscsa.edu
}

Received: 11 December 2018; Accepted: 15 January 2019; Published: 17 January 2019

\begin{abstract}
Non-culture-based diagnostics have been developed to help establish an early diagnosis of invasive fungal infection. Studies have shown that these tests can significantly impact the diagnosis of infection in high risk patients. Aspergillus galactomannan EIA testing is well-recognized as an important adjunct to the diagnosis of invasive aspergillosis and can be detected in serum, bronchoalveolar lavage and other fluids. Galactomannan testing used along with PCR testing has been shown to be effective when integrated into care paths for high risk patients for both diagnoses and as a surrogate marker for outcome when used in serial testing. Beta-D-glucan assays are non-specific for several fungal genera including Aspergillus and Candida and in high risk patients have been an important tool to augment the diagnosis. Lateral flow technology using monoclonal antibodies to Aspergillus are available that allow rapid testing of clinical samples. While standard PCR for Candida remains investigational, T2 magnetic resonance allows for the rapid diagnosis of Candida species from blood cultures. Aspergillus PCR has been extensively validated with standardized approaches established for these methods and will be included in the diagnostic criteria in the revised European Organization for Research and Treatment of Cancer/Mycoses Study Group (EORTC-MSG) definitions. Finally, these non-culture-based tests can be used in combination to significantly increase the detection of invasive mycoses with the ultimate aim of establishing an early diagnosis of infection.
\end{abstract}

Keywords: invasive fungal infection; non-culture-based diagnostics; aspergillosis; candidiasis; Aspergillus PCR; galactomannan; lateral flow; beta-D-glucan; T2 Candida

\section{Introduction}

Invasive fungal infections remain a significant cause of morbidity and mortality in immunocompromised patients. The diagnosis of these infections is delayed due to lack of positive cultures from blood or from tissues, which require invasive procedures to obtain and are often difficult to perform in these critically ill patients. Non-culture-based diagnostics have been developed to help establish an early diagnosis of infection with the aim of allowing prompt initiation of antifungal therapy and improving patient outcomes.

Non-culture-based diagnostics have been developed for both Aspergillus and Candida along with other opportunistic fungal pathogens [1]. These assays have been largely focused on Aspergillus due to its prominence as the most common mold in immunocompromised hosts and for Candida, to augment diagnosis in the setting of negative or delayed positive blood cultures [2]. Assays are being developed for opportunistic pathogens including mucorales but are less widely available in clinical settings [3,4]. Additionally, for endemic fungi including Coccidioides, Histoplasma, and Blastomyces as well as Cryptococcus, non-culture-based methods for diagnosis are available but beyond the scope of this review. 
Non-culture-based tests include galactomannan, which can be used in serum, bronchoalveolar lavage fluid and other samples; beta-D-glucan, a non-specific assay for Aspergillus, Candida, and other mycoses; lateral flow technology using an Aspergillus monoclonal antibody; and others including Candida PCR and T2 magnetic resonance. Aspergillus PCR has been extensively validated for standardized methodologies and is now included in the recent EORTC/MSG definition updates. In this review, the data supporting the use of clinically available non-culture-based methods for Aspergillus and Candida will be discussed and their utility alone and in combination will be summarized.

\section{Risk Factors and Impact of Diagnostics}

When approaching the use of these assays in the clinical setting, it is important to recognize the risk factors associated with invasive fungal infection, in order to improve the utility of their performance. The risk factors for invasive fungal infections have been extensively evaluated, as they significantly impact the incidence of invasive fungal infections and thus the performance of diagnostic assays. Herbrecht and colleagues outlined host factors for 'high risk patients', including those with allogeneic stem cell transplants, acute myelogenous leukemia/myelodysplastic syndrome, chronic granulomatous disease and others; those at 'intermediate' risk, including solid organ transplant recipients, other haematological malignancies, uncontrolled HIV infection, and others; while 'low risk' includes patients with autologous stem cell transplants, kidney transplant, solid tumors and others [5]. Additional risk factors influence the host condition, including innate immune defects; underlying conditions (neutropenia, graft vs. host disease, corticosteroid use, other biological agents, chemotherapy, etc); environmental factors and exposures; and other co-morbidities (diabetes, respiratory diseases and others) [5].

Fleming and colleagues established a risk stratification for patients with hematological malignancies. High risk patients are those with $>10 \%$ incidence of invasive fungal disease, that is, patients with prolonged neutropenia $\left(<0.1 \times 10^{9} / \mathrm{L}\right.$ for $>3$ weeks or $<0.5 \times 10^{9} / \mathrm{L}$ for $>5$ weeks), unrelated, mismatched or cord blood donor SCT, graft vs. host disease (GVHD), high doses of corticosteroids, certain chemotherapeutic agents (high-dose cytarabine, fludarabine, alemtuzumab, and others), and certain hematological malignancies (acute myelogenous leukemia (AML) and acute lymphocytic leukemia (ALL)) [6]. An intermediate risk group with an incidence of invasive fungal disease of around $10 \%$ includes those with less profound neutropenia $\left(0.1-0.5 \times 10^{9} / \mathrm{L}\right.$ for $3-5$ weeks or $0.1-0.5 \times 10^{9} / \mathrm{L}$ for $<3$ weeks with lymphopenia), while low risk patients $(\sim 2 \%$ incidence of invasive fungal disease) would include autologous SCT and lymphoma [6]. Clearly, these patients with hematological malignancies have significant differences in risk for fungal infection and it becomes critically important to consider these differences when interpreting the clinical utility of these non-culture-based diagnostic tests, based on the prior probability of disease.

It is also critical to recognize the impact that diagnostic tests can have on underestimates of infection and the impact that diagnosis has on outcomes. Ceesay and colleagues evaluated a series of 203 patients with hematological malignancies using a strict diagnostic algorithm including a pre-treatment computed tomography of the chest, twice weekly serum galactomannan, and beta-D-glucan with suspicion of infection and tissue for diagnosis [7]. The series showed that the incidence of established infection rose from $10.5 \%$ with galactomannan alone to almost $20 \%$ with a combination of galactomannan and beta-D-glucan, and was $21.1 \%$ when all tests were combined. Furthermore, at $45 \%$, the survival of those with proven/probable infection was significantly lower than those with possible disease, at $66 \%$. The survival rate was $87 \%$ for those without infection $(p<0.001)$, supporting the importance of using these tools to establish a diagnosis of invasive fungal disease.

\section{Galactomannan}

The detection of galactomannan by EIA is a well-established and extensively studied method for the diagnosis of invasive aspergillosis [2,8,9]. Monoclonal antibody EB-A2 is used in a double sandwich ELISA to detect an antigenic side chain of $\beta$-1,5-galactofuronosyl with a linear core of mannan with 
$\alpha 1,2$ and $\alpha 1,6$ linkages [10]. Early studies by Maertens and others prior to the availability of anti-mold prophylaxis showed a sensitivity and specificity of $89 \%$ and $98 \%$, respectively [11]. Subsequently, other studies showed more limited sensitivity (43-70\%) but with specificity of 70-93\% and studies confirmed the validation of a galactomannan index (GMI) of 0.5 as the threshold for positivity $[12,13]$. It was also appreciated that there were several sources for false-positive results including weakly positive samples, cross-reactivity with other fungi and antibiotics (such as pipercillin-tazobactam, which has now been resolved) [14]. Other sources of false-positives such as dietary reactivity, laboratory contamination or fluids for bronchoalveolar lavage (such as plasmalyte which also appears to have resolved) may continue [14-19]. A number of other factors may affect the performance of the galactomannan assay, including biological factors (such as site of infection, Aspergillus species, prior use of antifungals, renal clearance, hepatic metabolism, underlying condition, storage of the samples, and others) and epidemiological factors (such as the prevalence of disease, sampling strategies and definitions for positive results) [17]. An important study by Duarte and colleagues showed the dramatic impact of antifungal prophylaxis on the strategy of serial sampling [20]. In this study the positive predictive value dropped to $11.8 \%$, but was still useful with a positive predictive value of $89.6 \%$ when used for the diagnosis of invasive fungal disease on suspicion of disease [20].

Galactomannan testing in bronchoalveolar (BAL) lavage fluid is very useful for establishing a diagnosis of infection. This method is more sensitive than cytology, culture, transbronchial biopsy or serum galactomannan testing [21]. Galactomannan detection increased the sensitivity from serum from $47 \%$ to $85 \%$ from BAL, with a positive predictive value approaching $100 \%$ and with a BAL GMI of $<0.5$, indicating that it is useful to exclude the diagnosis in high risk patients with hematological malignancies [22,23]. On the other hand, in solid organ transplant patients, false positive results were more likely in lung transplant patients and in those colonized with Aspergillus [24]. The utility of galactomannan has been shown to improve in combination with PCR. Reinwald and colleagues showed that positivity from BAL of both galactomannan (at a GMI of $>0.5$ ) with positive PCR results highly supported the diagnosis [25]. Notably, the consensus regarding the cutoff value for a positive BAL galactomannan is still lacking, as performance will also vary in different patient settings (i.e., hematological malignancy, solid organ transplantation, intensive care units, etc.) so that a higher cutoff threshold (GMI > 1.0) may correlate with better diagnostic utility [26,27].

Galactomannan along with PCR was evaluated in a diagnostic vs. empirical therapy approach by Morrissey and colleagues [28]. In this study, empirical antifungal therapy was reduced from $32 \%$ in the standard diagnosis group to $15 \%$ in the biomarker diagnosis group, even though the rate of proven/probable disease was increased from 1\% to $15 \%$ [28]. Mortality was $15 \%$ in the standard diagnosis group and $10 \%$ in the biomarker group [28]. In this study, 10/39 (26\%) of the patients receiving empirical antifungal therapy would have been diagnosed with invasive aspergillosis a median of 4 days earlier and 5/6 (83\%) of those who died from invasive aspergillosis would have been diagnosed a median of 7 days earlier.

Finally, serial galactomannan measurements can also be used for the assessment of outcomes. Chai and colleagues showed that a GMI reduction of $>35 \%$ between baseline and week 1 predicted a satisfactory response in patients enrolled in the Global Voriconazole Aspergillosis trial [29]. Poorer responses occurred with increasing GMI after 2 weeks. Similarly, outcomes are better in patients who become GMI negative during their course of treatment $[9,30]$.

\section{Beta-D-Glucan}

Testing with (1-3)- $\beta$-D-glucan activates Limulus amebocyte lysate through factor $G$ initiation of the complement cascade [31]. The output can be measured using a chromogenic substrate (Fungitell (Associates of Cape Cod, Falmouth, MA) and others or by turbidity after gel clot (Wako Pure Chemical Industries, Osaka, Japan) [31]. These assays detect a number of important fungal genera including Aspergillus, Candida, Trichosporon, Fusarium, and Exerohilum but not mucorales or cryptococcosis [32]. Early studies showed the value of the assay in candidemia and in invasive fungal disease in patients 
with acute leukemia, which allowed regulatory clearance as well as inclusion in the European Organization for Research and Treatment of Cancer/Mycoses Study Group (EORTC-MSG) definitions for fungal infection $[33,34]$.

More recent studies in invasive candidiasis have evaluated the role of beta-D-glucan with Candida, real-time PCR and blood cultures [35]. In this study, both PCR and beta-D-glucan were more sensitive for deep seated Candida infection: $88 \%$ and $62 \%$, respectively, vs. $17 \%$ for blood cultures. Beta-D-glucan was shown to anticipate the diagnosis of blood culture-negative intraabdominal candidiasis and may be an important adjunct to that diagnosis [36].

Beta-D-glucan testing has also shown utility in specific clinical settings. In pneumocystis pneumonia, beta-D-glucan levels are frequently extremely elevated $(>500 \mathrm{pg} / \mathrm{mL})$ so that in a likely clinical setting more invasive testing might be obviated [37]. In addition, during an outbreak of fungal meningitis due to contaminated steroids, it was recognized that Exserohilum spp. (the etiological cause of the outbreak) produces high levels of beta-D-glucan [38]. It was subsequently shown that beta-D-glucan is highly sensitive for the diagnosis and is correlated with response to therapy [38].

\section{Lateral Flow Technology in Invasive Aspergillosis}

Lateral flow assays for invasive aspergillosis offer the potential for a rapid diagnosis, ease of performance and point of care use. A murine monoclonal antibody, JF4, binds to an extracellular glycoprotein antigen secreted during the growth of Aspergillus and distinguishes between hyphae and conidia [39]. Earlier and more consistent detection compared to beta-D-glucan or galactomannan was seen in pre-clinical models [39-41]. A prototype lateral flow device (LFD) was evaluated in high risk hematological malignancy patients and was shown to improve the diagnostic yield, especially when combined with galactomannan and PCR [42-44]. In BAL samples this assay had an overall sensitivity of $73 \%$ and a specificity of $90 \%$ [45,46]. A recent European conformity (CE)-marked LFD (OLM Diagnostics, Newcastle-on-Tyne, UK) showed similar sensitivity to the prototype device of $71 \%$, but with an improved sensitivity of $100 \%$ [46]. Another lateral flow assay for Aspergillus (IMMY, Norman, OK, USA) was compared in a small study to the LFD in BAL fluid and showed similar sensitivity and specificities of $89 \%$ and $88 \%$ [47].

\section{T2 Magnetic Resonance}

While real-time PCR for Candida remains investigational, the use of T2 magnetic resonance using nanoparticles has been cleared for clinical use (T2 Candida, T2 Biosystems, Lexington, MA, USA) [48-50]. The assay requires a dedicated instrument and detects Candida species directly from blood samples, but unlike blood cultures it does not require viable organisms [51]. The assay detects five major Candida species that are grouped based on typical susceptibility patterns. Using spiked blood samples, it was shown that this method could detect C. albicans/C. tropicalis, C. parapsilosis, and C. krusei/C. glabrata at a sensitivity of $91.1 \%$ with a time to positivity of $4.4 \mathrm{hrs}$ and a limit of detection of 1-3 CFU/mL [52]. In a follow-up study of patients with candidemia, follow-up blood cultures were compared with the T2 Candida assay and showed T2 Candida positivity in 45\% of the follow-up blood cultures compared to $24 \%$ with standard culture techniques. These results suggest that this method could be used to detect candidemia in patients who are receiving empirical antifungal therapy and could be very useful in allowing empirical therapy to be discontinued in patients with negative results [51]. In addition, $\mathrm{T} 2$ shortened the time to positivity to $<3 \mathrm{~h}$ and identified a bloodstream infection not detected by blood cultures, while retaining sensitivity during antifungal therapy.

\section{Aspergillus PCR Development and Standardization}

PCR for Aspergillus species has been evaluated for more than 25 years to fulfil the mycological criteria for the diagnosis of invasive fungal disease [53]. The EORTC/MSG clinical definitions were published in 2002 and revised in 2008 and provided important guidelines for criteria of proven, probable and possible invasive fungal disease, in order to facilitate clinical research including drug 
trials, epidemiology, and diagnostic tests [54,55]. These were not intended as a guide to clinical practice, but the elements of the definitions have been widely used as an adjunct to clinical management. The 2008 definitions defined proven disease when fungi are detected in specimens from a sterile body site or in a biopsy. In contrast, possible and probable disease both require a host factor and a clinical feature. Possible disease is assigned in the absence of any mycological criteria. Probable disease is assigned when the mycological criteria are met by direct mycology-cytology, direct microscopy or culture, or indirectly, by the detection of galactomannan and beta-D-glucan, but not PCR, due to the lack of standardization and validation [55]. Subsequently, the European Aspergillus PCR Initiative (EAPCRI) was established to develop a standard for Aspergillus PCR methodology so that PCR could be incorporated into future consensus definitions for invasive fungal disease [56].

Initial efforts included a systemic review published in 2009 of more than 10,000 blood, serum or plasma samples from 1618 patients at risk for Aspergillus and concluded at that time that two positive tests were required to confirm the diagnosis due to the specificity of these tests and a single PCR-negative result was sufficient to exclude a diagnosis of invasive aspergillosis [57]. However, it was also noted that there was a lack of homogeneity of the PCR methods so that subsequent collaboration aimed at a formal validation of that process.

Aspergillus standardization was evaluated through a collaboration of 21 European medical centers [56]. While specific protocols were not developed, compliant and non-compliant centers were noted. Twelve centers used 10 different DNA extraction protocols and nine different PCR amplification procedures that were compliant. Nine centers used seven extraction protocols and seven different PCR amplification procedures that were noncompliant. The sensitivity, specificity, and diagnostic odds ratio (DOR) of compliant centers were $88.7 \%, 91.6 \%$, and 119.9, respectively, for non-compliant centers these were and $57.7 \%, 77.2 \%$, and 8.9 , respectively. These results were highly statistically significant for sensitivity $(p=0.008)$ and DOR $(p=0.006)$. The factors with the most influence on PCR included compliance with the extraction method, bead beating of the sample, and use of an internal control PCR. This led to recommendations for the whole blood PCR of $>3 \mathrm{~mL}$ of blood, bead-beating to lyse fungal cells, a real time PCR platform with multi-copy targets with specific probes, internal control PCR and others [56]. Subsequent work showed that most of the Aspergillus protocols used to test serum generated satisfactory analytical performance and that the testing serum required less standardization [58]. Additional evaluation evaluated plasma vs. serum and showed improved sensitivity with plasma with PCR positivity occurring earlier, while maintaining methodological simplicity [59].

An extensive Cochrane study was performed for the diagnosis of invasive aspergillosis in immunocompromised people [60]. The studies included were those that compared the results of blood PCR tests with reference to the EORTC/MSG standard and included false positive, true positive, false negative and true negative results and that evaluated the test(s) prospectively in cohorts from patients at high risk for invasive aspergillosis. Overall, 1672 records were identified and 155 were screened to eventually include 18 studies for the meta-analysis [60]. For one single PCR specimen a sensitivity of $80.5 \%$ and a specificity of 78.5 were reported in 17 studies. For two or more PCR specimens the sensitivity decreased to $57.9 \%$ and the specificity increased to $96.2 \%$. The authors concluded that PCR shows moderate diagnostic accuracy when used for screening and has a high negative predictive value (NPV) that allows the diagnosis of invasive aspergillosis to be ruled out. A poor positive predictive value (PPV) when the prevalence of disease is low, limits the ability to rule in a diagnosis. Since other non-culture-based methods (such as galactomannan) detect different aspects of the disease, combinations of both together are likely to be more useful. PCR used in combination with galactomannan has been shown to improve the detection of invasive aspergillosis before detection by CT findings in high risk hematological patients [61] and to improve the sensitivity and specificity of testing [62]. In a randomized controlled trial, a combined monitoring strategy based on serum galactomannan and Aspergillus PCR was associated with an earlier diagnosis of invasive aspergillosis [63]. Robust recommendations for plasma and serum are available that establish a 
'standard for PCR' but not a 'standard method for PCR' so that Aspergillus PCR will be included in the revised EORTC/MSG consensus definitions [64].

\section{Clinical Utility and Summary}

The importance of assessing risk and using non-culture-based diagnostics for invasive fungal disease is clear. Several methods have been evaluated and validated for clinical use including galactomannan, beta-D-glucan, lateral flow technology, T2 magnetic resonance, PCR and others. Non-culture-based biomarkers provide more reliable negative than positive predictive values. When the prevalence of disease is higher than $15 \%$, negative test results exclude the diagnosis, while positive test results include the diagnosis. Clinicians and laboratories need to consider when a test is being requested for screening (when a patient is at risk for invasive fungal disease) as opposed to diagnosis (in which there is a high clinical suspicion of an invasive fungal disease), which will have a substantially higher pre-test probability. Finally, combinations of these tests may provide the greatest benefit in establishing a diagnosis of invasive fungal disease.

Author Contributions: Conceptualization, writing—review and editing, T.F.P and J.P.D.

Funding: There was no financial support for this work.

Conflicts of Interest: For activities outside of the submitted work, T.F.P. has been a consultant for or served on advisory boards to Astellas, Basilea, Gilead, Merck, Pfizer, Scynexis, and Toyama. J.P.D is a member of the European Aspergillus PCR initiative (EAPCRI).

\section{References}

1. Mikulska, M.; Furfaro, E.; Viscoli, C. Non-cultural methods for the diagnosis of invasive fungal disease. Expert Rev. Anti Infect. Ther. 2015, 13, 103-117. [CrossRef] [PubMed]

2. Hope, W.W.; Walsh, T.J.; Denning, D.W. Laboratory diagnosis of invasive aspergillosis. Lancet Infect. Dis. 2005, 5, 609-622. [CrossRef]

3. Baldin, C.; Soliman, S.S.M.; Jeon, H.H.; Alkhazraji, S.; Gebremariam, T.; Gu, Y.; Bruno, V.M.; Cornely, O.A.; Leather, H.L.; Sugrue, M.W.; et al. Pcr-based approach targeting mucorales-specific gene family for diagnosis of mucormycosis. J. Clin. Microbiol. 2018, 56. [CrossRef] [PubMed]

4. Scherer, E.; Iriart, X.; Bellanger, A.P.; Dupont, D.; Guitard, J.; Gabriel, F.; Cassaing, S.; Charpentier, E.; Guenounou, S.; Cornet, M.; et al. Quantitative pcr (qpcr) detection of mucorales DNA in bronchoalveolar lavage fluid to diagnose pulmonary mucormycosis. J. Clin. Microbiol. 2018, 56. [CrossRef] [PubMed]

5. Herbrecht, R.; Bories, P.; Moulin, J.C.; Ledoux, M.P.; Letscher-Bru, V. Risk stratification for invasive aspergillosis in immunocompromised patients. Ann. N. Y. Acad. Sci. 2012, 1272, 23-30. [CrossRef]

6. Fleming, S.; Yannakou, C.K.; Haeusler, G.M.; Clark, J.; Grigg, A.; Heath, C.H.; Bajel, A.; van Hal, S.J; Chen, S.C.; Milliken, S.T.; et al. Consensus guidelines for antifungal prophylaxis in haematological malignancy and haemopoietic stem cell transplantation, 2014. Intern. Med. J. 2014, 44, 1283-1297. [CrossRef] [PubMed]

7. Ceesay, M.M.; Desai, S.R.; Berry, L.; Cleverley, J.; Kibbler, C.C.; Pomplun, S.; Nicholson, A.G.; Douiri, A.; Wade, J.; Smith, M.; et al. A comprehensive diagnostic approach using galactomannan, targeted beta-d-glucan, baseline computerized tomography and biopsy yields a significant burden of invasive fungal disease in at risk haematology patients. Br. J. Haematol. 2015, 168, 219-229. [CrossRef] [PubMed]

8. Miceli, M.H.; Maertens, J. Role of non-culture-based tests, with an emphasis on galactomannan testing for the diagnosis of invasive aspergillosis. Semin. Respir. Crit. Care Med. 2015, 36, 650-661.

9. Mercier, T.; Guldentops, E.; Lagrou, K.; Maertens, J. Galactomannan, a surrogate marker for outcome in invasive aspergillosis: Finally coming of age. Front. Microbiol. 2018, 9, 661. [CrossRef]

10. Stynen, D.; Goris, A.; Sarfati, J.; Latge, J.P. A new sensitive sandwich enzyme-linked immunosorbent assay to detect galactofuran in patients with invasive aspergillosis. J. Clin. Microbiol. 1995, 33, 497-500.

11. Maertens, J.; Verhaegen, J.; Lagrou, K.; Van Eldere, J.; Boogaerts, M. Screening for circulating galactomannan as a noninvasive diagnostic tool for invasive aspergillosis in prolonged neutropenic patients and stem cell transplantation recipients: A prospective validation. Blood 2001, 97, 1604-1610. [CrossRef] [PubMed] 
12. Marr, K.A.; Balajee, S.A.; McLaughlin, L.; Tabouret, M.; Bentsen, C.; Walsh, T.J. Detection of galactomannan antigenemia by enzyme immunoassay for the diagnosis of invasive aspergillosis: Variables that affect performance. J. Infect. Dis. 2004, 190, 641-649. [CrossRef] [PubMed]

13. Herbrecht, R.; Letscher-Bru, V.; Oprea, C.; Lioure, B.; Waller, J.; Campos, F.; Villard, O.; Liu, K.L.; Natarajan-Ame, S.; Lutz, P.; et al. Aspergillus galactomannan detection in the diagnosis of invasive aspergillosis in cancer patients. J. Clin. Oncol. 2002, 20, 1898-1906. [CrossRef] [PubMed]

14. Mikulska, M.; Furfaro, E.; Del Bono, V.; Raiola, A.M.; Ratto, S.; Bacigalupo, A.; Viscoli, C. Piperacillin/tazobactam (tazocin) seems to be no longer responsible for false-positive results of the galactomannan assay. J. Antimicrob. Chemother. 2012, 67, 1746-1748. [CrossRef] [PubMed]

15. Machetti, M.; Majabo, M.J.; Furfaro, E.; Solari, N.; Novelli, A.; Cafiero, F.; Viscoli, C. Kinetics of galactomannan in surgical patients receiving perioperative piperacillin/tazobactam prophylaxis. J. Antimicrob. Chemother. 2006, 58, 806-810. [CrossRef] [PubMed]

16. Maertens, J.; Theunissen, K.; Verhoef, G.; Van Eldere, J. False-positive aspergillus galactomannan antigen test results. Clin. Infect. Dis. 2004, 39, 289-290. [CrossRef]

17. Mennink-Kersten, M.A.; Donnelly, J.P.; Verweij, P.E. Detection of circulating galactomannan for the diagnosis and management of invasive aspergillosis. Lancet Infect. Dis. 2004, 4, 349-357. [CrossRef]

18. Spriet, I.; Lagrou, K.; Maertens, J.; Willems, L.; Wilmer, A.; Wauters, J. Plasmalyte: No longer a culprit in causing false-positive galactomannan test results. J. Clin. Microbiol. 2016, 54, 795-797. [CrossRef]

19. Viscoli, C.; Machetti, M.; Cappellano, P.; Bucci, B.; Bruzzi, P.; Van Lint, M.T.; Bacigalupo, A. False-positive galactomannan platelia aspergillus test results for patients receiving piperacillin-tazobactam. Clin. Infect. Dis. 2004, 38, 913-916. [CrossRef]

20. Duarte, R.F.; Sanchez-Ortega, I.; Cuesta, I.; Arnan, M.; Patino, B.; Fernandez de Sevilla, A.; Gudiol, C.; Ayats, J.; Cuenca-Estrella, M. Serum galactomannan-based early detection of invasive aspergillosis in hematology patients receiving effective antimold prophylaxis. Clin. Infect. Dis. 2014, 59, 1696-1702. [CrossRef]

21. Nguyen, M.H.; Leather, H.; Clancy, C.J.; Cline, C.; Jantz, M.A.; Kulkarni, V.; Wheat, L.J.; Wingard, J.R. Galactomannan testing in bronchoalveolar lavage fluid facilitates the diagnosis of invasive pulmonary aspergillosis in patients with hematologic malignancies and stem cell transplant recipients. Biol. Blood Marrow Transplant. 2011, 17, 1043-1050. [CrossRef] [PubMed]

22. Becker, M.J.; Lugtenburg, E.J.; Cornelissen, J.J.; Van Der Schee, C.; Hoogsteden, H.C.; De Marie, S. Galactomannan detection in computerized tomography-based broncho-alveolar lavage fluid and serum in haematological patients at risk for invasive pulmonary aspergillosis. Br. J. Haematol. 2003, 121, $448-457$. [CrossRef] [PubMed]

23. D'Haese, J.; Theunissen, K.; Vermeulen, E.; Schoemans, H.; De Vlieger, G.; Lammertijn, L.; Meersseman, P.; Meersseman, W.; Lagrou, K.; Maertens, J. Detection of galactomannan in bronchoalveolar lavage fluid samples of patients at risk for invasive pulmonary aspergillosis: Analytical and clinical validity. J. Clin. Microbiol. 2012, 50, 1258-1263. [CrossRef] [PubMed]

24. Husain, S.; Paterson, D.L.; Studer, S.M.; Crespo, M.; Pilewski, J.; Durkin, M.; Wheat, J.L.; Johnson, B.; McLaughlin, L.; Bentsen, C.; et al. Aspergillus galactomannan antigen in the bronchoalveolar lavage fluid for the diagnosis of invasive aspergillosis in lung transplant recipients. Transplantation 2007, 83, 1330-1336. [CrossRef] [PubMed]

25. Reinwald, M.; Spiess, B.; Heinz, W.J.; Vehreschild, J.J.; Lass-Florl, C.; Kiehl, M.; Schultheis, B.; Krause, S.W.; Wolf, H.H.; Bertz, H.; et al. Diagnosing pulmonary aspergillosis in patients with hematological malignancies: A multicenter prospective evaluation of an aspergillus pcr assay and a galactomannan elisa in bronchoalveolar lavage samples. Eur. J. Haematol. 2012, 89, 120-127. [CrossRef] [PubMed]

26. Maertens, J.; Maertens, V.; Theunissen, K.; Meersseman, W.; Meersseman, P.; Meers, S.; Verbeken, E.; Verhoef, G.; Van Eldere, J.; Lagrou, K. Bronchoalveolar lavage fluid galactomannan for the diagnosis of invasive pulmonary aspergillosis in patients with hematologic diseases. Clin. Infect. Dis. 2009, 49, 1688-1693. [CrossRef] [PubMed]

27. Clancy, C.J.; Jaber, R.A.; Leather, H.L.; Wingard, J.R.; Staley, B.; Wheat, L.J.; Cline, C.L.; Rand, K.H.; Schain, D.; Baz, M.; et al. Bronchoalveolar lavage galactomannan in diagnosis of invasive pulmonary aspergillosis among solid-organ transplant recipients. J. Clin. Microbiol. 2007, 45, 1759-1765. [CrossRef] 
28. Morrissey, C.O.; Chen, S.C.; Sorrell, T.C.; Milliken, S.; Bardy, P.G.; Bradstock, K.F.; Szer, J.; Halliday, C.L.; Gilroy, N.M.; Moore, J.; et al. Galactomannan and pcr versus culture and histology for directing use of antifungal treatment for invasive aspergillosis in high-risk haematology patients: A randomised controlled trial. Lancet Infect. Dis. 2013, 13, 519-528. [CrossRef]

29. Chai, L.Y.; Kullberg, B.J.; Johnson, E.M.; Teerenstra, S.; Khin, L.W.; Vonk, A.G.; Maertens, J.; Lortholary, O.; Donnelly, P.J.; Schlamm, H.T.; et al. Early serum galactomannan trend as a predictor of outcome of invasive aspergillosis. J. Clin. Microbiol. 2012, 50, 2330-2336. [CrossRef]

30. Maertens, J.; Buve, K.; Theunissen, K.; Meersseman, W.; Verbeken, E.; Verhoef, G.; Van Eldere, J.; Lagrou, K. Galactomannan serves as a surrogate endpoint for outcome of pulmonary invasive aspergillosis in neutropenic hematology patients. Cancer 2009, 115, 355-362. [CrossRef]

31. Obayashi, T.; Negishi, K.; Suzuki, T.; Funata, N. Reappraisal of the serum (1->3)-beta-d-glucan assay for the diagnosis of invasive fungal infections-a study based on autopsy cases from 6 years. Clin. Infect. Dis. 2008, 46, 1864-1870. [CrossRef] [PubMed]

32. Odabasi, Z.; Paetznick, V.L.; Rodriguez, J.R.; Chen, E.; McGinnis, M.R.; Ostrosky-Zeichner, L. Differences in beta-glucan levels in culture supernatants of a variety of fungi. Med. Mycol. 2006, 44, 267-272. [CrossRef] [PubMed]

33. Odabasi, Z.; Mattiuzzi, G.; Estey, E.; Kantarjian, H.; Saeki, F.; Ridge, R.J.; Ketchum, P.A.; Finkelman, M.A.; Rex, J.H.; Ostrosky-Zeichner, L. Beta-d-glucan as a diagnostic adjunct for invasive fungal infections: Validation, cutoff development, and performance in patients with acute myelogenous leukemia and myelodysplastic syndrome. Clin. Infect. Dis. 2004, 39, 199-205. [CrossRef]

34. Ostrosky-Zeichner, L.; Alexander, B.D.; Kett, D.H.; Vazquez, J.; Pappas, P.G.; Saeki, F.; Ketchum, P.A.; Wingard, J.; Schiff, R.; Tamura, H.; et al. Multicenter clinical evaluation of the (1->3) beta-d-glucan assay as an aid to diagnosis of fungal infections in humans. Clin. Infect. Dis. 2005, 41, 654-659. [CrossRef]

35. Nguyen, M.H.; Wissel, M.C.; Shields, R.K.; Salomoni, M.A.; Hao, B.; Press, E.G.; Shields, R.M.; Cheng, S.; Mitsani, D.; Vadnerkar, A.; et al. Performance of candida real-time polymerase chain reaction, beta-d-glucan assay, and blood cultures in the diagnosis of invasive candidiasis. Clin. Infect. Dis. 2012, 54, 1240-1248. [CrossRef] [PubMed]

36. Tissot, F.; Lamoth, F.; Hauser, P.M.; Orasch, C.; Fluckiger, U.; Siegemund, M.; Zimmerli, S.; Calandra, T.; Bille, J.; Eggimann, P.; et al. Beta-glucan antigenemia anticipates diagnosis of blood culture-negative intraabdominal candidiasis. Am. J. Respir. Crit. Care Med. 2013, 188, 1100-1109. [CrossRef] [PubMed]

37. Koo, S.; Baden, L.R.; Marty, F.M. Post-diagnostic kinetics of the (1 -> 3)-beta-d-glucan assay in invasive aspergillosis, invasive candidiasis and pneumocystis jirovecii pneumonia. Clin. Microbiol. Infect. 2012, 18, E122-E127. [CrossRef]

38. Litvintseva, A.P.; Lindsley, M.D.; Gade, L.; Smith, R.; Chiller, T.; Lyons, J.L.; Thakur, K.T.; Zhang, S.X.; Grgurich, D.E.; Kerkering, T.M.; et al. Utility of (1-3)-beta-d-glucan testing for diagnostics and monitoring response to treatment during the multistate outbreak of fungal meningitis and other infections. Clin. Infect. Dis. 2014, 58, 622-630. [CrossRef]

39. Thornton, C.R. Development of an immunochromatographic lateral-flow device for rapid serodiagnosis of invasive aspergillosis. Clin. Vaccine Immunol. 2008, 15, 1095-1105. [CrossRef]

40. Thornton, C.R. Breaking the mould-novel diagnostic and therapeutic strategies for invasive pulmonary aspergillosis in the immune deficient patient. Expert Rev. Clin. Immunol. 2014, 10, 771-780. [CrossRef]

41. Wiederhold, N.P.; Thornton, C.R.; Najvar, L.K.; Kirkpatrick, W.R.; Bocanegra, R.; Patterson, T.F. Comparison of lateral flow technology and galactomannan and (1->3)-beta-d-glucan assays for detection of invasive pulmonary aspergillosis. Clin. Vaccine Immunol. 2009, 16, 1844-1846. [CrossRef] [PubMed]

42. Eigl, S.; Prattes, J.; Lackner, M.; Willinger, B.; Spiess, B.; Reinwald, M.; Selitsch, B.; Meilinger, M.; Neumeister, P.; Reischies, F.; et al. Multicenter evaluation of a lateral-flow device test for diagnosing invasive pulmonary aspergillosis in icu patients. Crit. Care 2015, 19, 178. [CrossRef] [PubMed]

43. Hoenigl, M.; Prattes, J.; Spiess, B.; Wagner, J.; Prueller, F.; Raggam, R.B.; Posch, V.; Duettmann, W.; Hoenigl, K.; Wolfler, A.; et al. Performance of galactomannan, beta-D-glucan, aspergillus lateral-flow device, conventional culture, and pcr tests with bronchoalveolar lavage fluid for diagnosis of invasive pulmonary aspergillosis. J. Clin. Microbiol. 2014, 52, 2039-2045. [CrossRef] [PubMed] 
44. White, P.L.; Parr, C.; Thornton, C.; Barnes, R.A. Evaluation of real-time pcr, galactomannan enzyme-linked immunosorbent assay (elisa), and a novel lateral-flow device for diagnosis of invasive aspergillosis. J. Clin. Microbiol. 2013, 51, 1510-1516. [CrossRef] [PubMed]

45. Willinger, B.; Lackner, M.; Lass-Florl, C.; Prattes, J.; Posch, V.; Selitsch, B.; Eschertzhuber, S.; Honigl, K.; Koidl, C.; Sereinigg, M.; et al. Bronchoalveolar lavage lateral-flow device test for invasive pulmonary aspergillosis in solid organ transplant patients: A semiprospective multicenter study. Transplantation 2014, 98, 898-902. [CrossRef] [PubMed]

46. Hoenigl, M.; Eigl, S.; Heldt, S.; Duettmann, W.; Thornton, C.; Prattes, J. Clinical evaluation of the newly formatted lateral-flow device for invasive pulmonary aspergillosis. Mycoses 2018, 61, 40-43. [CrossRef]

47. Jenks, J.D.; Mehta, S.R.; Taplitz, R.; Aslam, S.; Reed, S.L.; Hoenigl, M. Point-of care diagnosis of invasive aspergillosis in in non-neutropenic patients: Aspergillus galactomannan lateral flow assay versus aspergillus-specific lateral flow device test in bronchoalveolar lavage. Mycoses 2018. [CrossRef]

48. Clancy, C.J.; Nguyen, M.H. T2 magnetic resonance for the diagnosis of bloodstream infections: Charting a path forward. J. Antimicrob. Chemother. 2018, 73, iv2-iv5. [CrossRef]

49. Clancy, C.J.; Nguyen, M.H. Non-culture diagnostics for invasive candidiasis: Promise and unintended consequences. J. Fungi (Basel) 2018, 4, 27. [CrossRef]

50. Zacharioudakis, I.M.; Zervou, F.N.; Mylonakis, E. T2 magnetic resonance assay: Overview of available data and clinical implications. J. Fungi (Basel) 2018, 4, 45. [CrossRef]

51. Clancy, C.J.; Pappas, P.G.; Vazquez, J.; Judson, M.A.; Kontoyiannis, D.P.; Thompson, G.R., 3rd; Garey, K.W.; Reboli, A.; Greenberg, R.N.; Apewokin, S.; et al. Detecting infections rapidly and easily for candidemia trial, part 2 (direct2): A prospective, multicenter study of the t2candida panel. Clin. Infect. Dis. 2018, 66, 1678-1686. [CrossRef]

52. Mylonakis, E.; Clancy, C.J.; Ostrosky-Zeichner, L.; Garey, K.W.; Alangaden, G.J.; Vazquez, J.A.; Groeger, J.S.; Judson, M.A.; Vinagre, Y.M.; Heard, S.O.; et al. T2 magnetic resonance assay for the rapid diagnosis of candidemia in whole blood: A clinical trial. Clin. Infect. Dis. 2015, 60, 892-899. [CrossRef] [PubMed]

53. Spreadbury, C.; Holden, D.; Aufauvre-Brown, A.; Bainbridge, B.; Cohen, J. Detection of aspergillus fumigatus by polymerase chain reaction. J. Clin. Microbiol. 1993, 31, 615-621. [PubMed]

54. Ascioglu, S.; Rex, J.H.; de Pauw, B.; Bennett, J.E.; Bille, J.; Crokaert, F.; Denning, D.W.; Donnelly, J.P.; Edwards, J.E.; Erjavec, Z.; et al. Defining opportunistic invasive fungal infections in immunocompromised patients with cancer and hematopoietic stem cell transplants: An international consensus. Clin. Infect. Dis. 2002, 34, 7-14. [CrossRef] [PubMed]

55. De Pauw, B.; Walsh, T.J.; Donnelly, J.P.; Stevens, D.A.; Edwards, J.E.; Calandra, T.; Pappas, P.G.; Maertens, J.; Lortholary, O.; Kauffman, C.A.; et al. Revised definitions of invasive fungal disease from the european organization for research and treatment of cancer/invasive fungal infections cooperative group and the national institute of allergy and infectious diseases mycoses study group (eortc/msg) consensus group. Clin. Infect. Dis. 2008, 46, 1813-1821.

56. White, P.L.; Bretagne, S.; Klingspor, L.; Melchers, W.J.; McCulloch, E.; Schulz, B.; Finnstrom, N.; Mengoli, C.; Barnes, R.A.; Donnelly, J.P.; et al. Aspergillus pcr: One step closer to standardization. J. Clin. Microbiol. 2010, 48, 1231-1240. [CrossRef]

57. Mengoli, C.; Cruciani, M.; Barnes, R.A.; Loeffler, J.; Donnelly, J.P. Use of pcr for diagnosis of invasive aspergillosis: Systematic review and meta-analysis. Lancet Infect. Dis. 2009, 9, 89-96. [CrossRef]

58. White, P.L.; Mengoli, C.; Bretagne, S.; Cuenca-Estrella, M.; Finnstrom, N.; Klingspor, L.; Melchers, W.J.; McCulloch, E.; Barnes, R.A.; Donnelly, J.P.; et al. Evaluation of aspergillus pcr protocols for testing serum specimens. J. Clin. Microbiol. 2011, 49, 3842-3848. [CrossRef]

59. White, P.L.; Barnes, R.A.; Springer, J.; Klingspor, L.; Cuenca-Estrella, M.; Morton, C.O.; Lagrou, K.; Bretagne, S.; Melchers, W.J.; Mengoli, C.; et al. Clinical performance of aspergillus pcr for testing serum and plasma: A study by the european aspergillus pcr initiative. J. Clin. Microbiol. 2015, 53, 2832-2837. [CrossRef]

60. Cruciani, M.; Mengoli, C.; Loeffler, J.; Donnelly, P.; Barnes, R.; Jones, B.L.; Klingspor, L.; Morton, O.; Maertens, J. Polymerase chain reaction blood tests for the diagnosis of invasive aspergillosis in immunocompromised people. Cochrane Database Syst. Rev. 2015, CD009551. [CrossRef]

61. Rogers, T.R.; Morton, C.O.; Springer, J.; Conneally, E.; Heinz, W.; Kenny, C.; Frost, S.; Einsele, H.; Loeffler, J. Combined real-time pcr and galactomannan surveillance improves diagnosis of invasive aspergillosis in high risk patients with haematological malignancies. Br. J. Haematol. 2013, 161, 517-524. [CrossRef] [PubMed] 
62. Arvanitis, M.; Anagnostou, T.; Mylonakis, E. Galactomannan and polymerase chain reaction-based screening for invasive aspergillosis among high-risk hematology patients: A diagnostic meta-analysis. Clin. Infect. Dis. 2015, 61, 1263-1272. [CrossRef] [PubMed]

63. Aguado, J.M.; Vazquez, L.; Fernandez-Ruiz, M.; Villaescusa, T.; Ruiz-Camps, I.; Barba, P.; Silva, J.T.; Batlle, M.; Solano, C.; Gallardo, D.; et al. Serum galactomannan versus a combination of galactomannan and polymerase chain reaction-based aspergillus DNA detection for early therapy of invasive aspergillosis in high-risk hematological patients: A randomized controlled trial. Clin. Infect. Dis. 2015, 60, 405-414. [CrossRef] [PubMed]

64. Barnes, R.A.; White, P.L.; Morton, C.O.; Rogers, T.R.; Cruciani, M.; Loeffler, J.; Donnelly, J.P. Diagnosis of aspergillosis by pcr: Clinical considerations and technical tips. Med. Mycol. 2018, 56, 60-72. [CrossRef] [PubMed]

(C) 2019 by the authors. Licensee MDPI, Basel, Switzerland. This article is an open access article distributed under the terms and conditions of the Creative Commons Attribution (CC BY) license (http://creativecommons.org/licenses/by/4.0/). 